\title{
AS ILUSÕES DA PARTICIPAÇÃO POPULAR NO SÉCULO XXI DE SÃO PAULO A BUENOS AIRES: UMA HOMENAGEM AO PROFESSOR FLÁVIO VILLAÇA'
}

\author{
Recebido em 29/01/2021, aprovado em 22/03/2021 \\ 10.30612/mvt.v8i14.15030 \\ Guilherme Giuliano Nicolau ${ }^{2}$ \\ Ivan Augusto Alves Pereira ${ }^{3}$ \\ Claudia Fabiana Guebel ${ }^{4}$
}

\begin{abstract}
RESUMO: Neste artigo, objetivamos uma análise comparativa sobre participação popular em metrópoles latino-americanas. Especificamente, comparamos a participação popular em audiências públicas nas cidades de São Paulo, em 2014, e Buenos Aires, em 2018. Metodologicamente, através da observação participante, acompanhamos audiências públicas relativas aos códigos urbanísticos das duas cidades, nos anos indicados, para estabelecer diferenças e similaridades entre as duas experiências e realizamos levantamentos históricos de ambas cidades em relação ao tema. Concluímos que, a despeito dos avanços em termos normativos com relação à cidadania, as condiçóes históricas para seu exercício são desfavoráveis tanto em lugares de participação mais avançada como em Buenos Aires ou mesmo nos avanços recentes em São Paulo.
\end{abstract}

Palavras-chave: Participação popular. Metrópoles latino-americanas. Audiências públicas. Urbanismo.

\section{THE ILLUSIONS OF POPULAR PARTICIPATION IN THE 21ST CENTURY FROM SÃO PAULO TO BUENOS AIRES: A TRIBUTE TO PROFESSOR FLÁVIO VILLAÇA}

\begin{abstract}
In this article, we present a comparative analysis of popular participation in Latin American metropolises. Specifically, we compare popular participation in public hearings in the cities of São Paulo, in 2014, and Buenos Aires, in 2018. Methodologically, through participant observation, we follow public hearings related to the urban codes of the two cities, in the indicated years, to establish differences and similarities between the two experiences and we carried out historical surveys of both cities in relation to the theme. We conclude that, despite advances in normative terms regarding citizenship, the historical conditions for its exercise are unfavorable both in places of more advanced participation such as Buenos Aires or even in recent advances in São Paulo.

$1 \quad$ Flávio Villaça foi professor da Faculdade de Arquitetura e Urbanismo da Universidade de São Paulo e trabalhou por 15 anos na Secretaria Municipal de Planejamento da Cidade de Sáo Paulo. Urbanista materialista e crítico tinha seu trabalho reconhecido pelos seus pares. Faleceu aos 91 anos, em 29 de março de 2021. Ver mais em ArchDaily (2021).

2 Departamento de Ciência Política da Universidade de São Paulo. Contato:ggnicolau@usp.br

3 Arquitetura, Universidade Belas Artes (SP). Contato: ivanalves@gmail.com

$4 \quad$ Facultad de Filosofia y Letras - Universidade de Buenos Aires (UBA). Contato: claudiaguebel@yahoo.com
\end{abstract}


Keywords: Popular participation. Latin American metropolises. Public Hearings. Urbanism.

\section{LAS ILUSIONES DE LA PARTICIPACIÓN POPULAR EN EL SIGLO XXI DE SÃO PAULO A BUENOS AIRES: UN HOMENAJE AL PROFESOR FLÁVIO VILLAÇA}

RESUMEN: En este artículo, apuntamos a un análisis comparativo de la participación popular en las metrópolis latinoamericanas. Específicamente, comparamos la participación popular en audiencias públicas en las ciudades de São Paulo, en 2014, y Buenos Aires, en 2018. Metodológicamente, a través de la observación participante, seguimos las audiencias públicas relacionadas con los códigos urbanos de las dos ciudades, en los ańos indicados, para establecer diferencias y similitudes entre las dos experiencias y realizamos relevamientos históricos de ambas ciudades en relación al tema. Concluimos que, a pesar de los avances normativos en materia de ciudadanía, las condiciones históricas para su ejercicio son desfavorables tanto en lugares de participación más avanzada como Buenos Aires o incluso en avances recientes en São Paulo.

Palabras-clave: Participación popular. Metrópolis latinoamericanas. Audiencias públicas. Urbanismo.

\section{INTRODUÇÃO}

$\mathrm{Na}$ intersecção entre mundos do trabalho e movimentos sociais, uma temática que tem sido particularmente relevante é o direito à cidade e, por extensão, a relação entre trabalhadores(as) e os governos municipais. Desta forma, analisar como são estabelecidos os códigos urbanísticos das cidades em sua relaçáo com os movimentos sociais, é particularmente relevante para pensar o trabalho. Ora, se um(a) trabalhador(a) deve se locomover longas distâncias para chegar em seu local de trabalho, então sua saúde, bem-estar, remuneração e etc. devem estar ligados ao acesso ao transporte público de qualidade. Embora essa discussáo extrapole questóes relacionadas estritamente ao comumente debatido na Sociologia do Trabalho (remuneração, jornada, previdência e etc.), é fundamental para repensar as fronteiras entre trabalho e cidade, renda e casa, público e privado.

Esse debate é relativamente novo no campo da Sociologia. Em primeiro lugar, no campo dos debates dos novos movimentos sociais pós Maio de 68 (ver, por exemplo, as produçóes de Touraine), prevaleceu certa ideia de equivalência entre trabalho e outras categorias sociológicas supostamente fundamentais, como ecologia. Decretou-se, inclusive, "o fim do trabalho" ou "adeus ao proletariado" (GORZ, 1982). Em segundo lugar, os debates acerca das "outras categorias", como raça e gênero, frequentemente apaga a centralidade do trabalho, ou mesmo da classe. Por fim, ter como referência Maio de 68 no campo da Sociologia nos convida a pensar formas eurocentradas de movimentos sociais. Ao unir movimentos sociais e trabalho nos debates sobre planejamento urbanístico e relaçóes municipais, buscamos minimamente questionar essas premissas.

Nosso trabalho tem como objetivo estabelecer uma comparação da participação popular em duas grandes cidades da América Latina: Sáo Paulo (2014) e Buenos Aires (2018). Nossas observaçóes têm origem em pesquisa de campo que acompanhou as audiências públicas realizadas para aprovação de seus respectivos códigos urbanísticos na última década.

Cabe-nos descrever a divisão de nossa pesquisa. Partimos por delimitar nosso marco teórico sobre o que entendemos por participaçáo política, a partir de trabalhos recentes que buscam entender o que se convencionou chamar "novíssimos movimentos sociais" que, apesar de ensaiado anteriormente, veio a confirmar-se com mais proeminência a partir dos anos 1990 em contraposição às reformas 
neoliberais. Em seguida, aplicaremos esse entendimento primeiramente à cidade de São Paulo e, em seguida, à cidade de Buenos Aires para então realizar comparaçôes entre as duas experiências por aproximaçóes e distanciamentos. Para isso nos utilizamos da "observação participativa”, já que em Buenos Aires estivemos presencialmente nas audiências e nas articulaçôes dos movimentos sociais sobre as questóes da cidade, junto à Universidade de Buenos Aires e ao Observatorio del Derecho a la Ciudad; no caso de São Paulo, também estivemos presentes nas açôes dos movimentos sociais pelo Direito à Cidade, principalmente os movimentos autonomistas ligados ao Comitê Contra a Copa, mas também como urbanista e funcionário da Prefeitura durante as audiências públicas do Plano Diretor da gestão Fernando Haddad. Por fim, tecemos nossas consideraçóes finais.

\section{TEORIA E MOVIMENTOS SOCIAIS}

Desde o surgimento do Estado Democrático de Direito, um novo entendimento passa a operar entre povo e poder, através de mecanismos de representação que estabelecem a relação entre sociedade civil e Estado. É nessa operação entre poder constituído e poder constituinte, que descreveremos a periodização dos movimentos sociais. Richard Day (2006) separa a prática dos movimentos sociais em três momentos.

Primeiramente, temos os Velhos Movimentos Sociais, característicos dos movimentos do século XIX até meados do século XX. Ele opera o antagonismo de classes para conquista da hegemonia, ou seja, conquista do Estado, como instrumento coercitivo que garanta a universalizaçáo das demandas frente aqueles que não consentem. Isso significa que somente funciona através de formas hierarquizadas (DAY, 2006, p. 718), um grupo dominante que alcança a hegemonia na sociedade civil, conquistando o aparato coercitivo do Estado que tem primazia sobre processos consensuais: "Nenhuma hegemonia sem poder estatal; nenhum poder de estado sem hegemonia" (DAY, 2006, p. 721).

Em seguida, temos os Novos Movimentos Sociais, característico dos movimentos sociais dos anos 1960 a 1980. Eles também operam por antagonismo e por disputa por hegemonia, mas é mais difuso por cada movimento demandando algo específico dentro uma miríade de opressões (racismo, machismo, homofobia, colonialismo e etc.) que não são reduzidas à classe. As atençôes transitaram para as políticas da vida cotidiana e transformação individual (DAY, 2006). Esse novo tipo de movimento é reformista: demanda e pressiona para que o sistema liberal incorpore demandas específicas à sua agenda é de protesto e reforma. É nesse momento que se incorporam mecanismos de participação como de audiência pública ${ }^{5}$ : incorporam-se as demandas da sociedade civil, mas sem a participação administrativa em sua execução. A orientação ainda é para o Estado, mas agora limitada aos grupos e suas demandas, mais que um grupo dominante com programa universalizante. Essa política do reconhecimento entra em uma razão circular que, ao mesmo tempo que demanda, reconhece o mesmo poder que oprime:

\footnotetext{
5 Mecanismos de participação direta eram conhecidos na Inglaterra desde o séc. XVI, apesar de raramente serem empregados. É conhecido como parte da organização de uma comunidade com o povoamento nos Estados Unidos (EUA), na Nova Inglaterra, através dos chamados 'Town Meetings'; havia diversos outros mecanismos expressos de participação política de diferentes qualidades. Porém, a audiência pública em seu formato moderno é conhecida por ter sido utilizada para o caso dos anarquistas de Chicago condenados na década de 1920, com Roosevelt. De qualquer forma, passou a ser mais recorrente no pós-guerra, em casos que se tornaram emblemáticos como no período do Mccartismo de perseguiçáo aos comunistas e também na política de "tolerância zero" do prefeito de Nova Iorque, tendo como um de seus alvos a "máfia" italiana. De qualquer forma, lembramos que foi também em grande medida utilizada pelo movimento dos direitos civis, nos anos $1960 \mathrm{em}$ diante. Tais mecanismos de participaçâo foram ainda mais ampliados a partir da década de 1990, quando também passaram a ser incorporados em diversas cidades do mundo, como Sáo Paulo e Nova Déli. Para mais, buscar o trabalho de Williamson e Fung (2004; 2005).
} 
Os NSMs se afastaram da política de coerção / consentimento de Lenin e Gramsci, para um território de hegemonia pelo que parece ser puro consentimento, ou seja, para o território da reforma liberal. Em vez de buscar o poder do Estado, os grupos subordinados começaram a se concentrar mais em persuadir uma formação hegemônica existente a alterar o funcionamento de certas instituições, ou infiltrar essas instituiçôes com um conjunto diferente de valores e, assim, construir uma contra-hegemonia (DAY, 2006, p. 727).

Por fim, temos os Novíssimos Movimentos Sociais, característico do movimento anti-globalização, dos anos 1990, como também dos movimentos que surgiram após a crise de 2008-2013. Eles são difusos como os Novos Movimentos Sociais, mas não buscam o reconhecimento ou a hegemonia via Estado; são uma constelação de singularidades (multidão) que agem em três níveis: resistência, insurreição e poder constituinte. Resumindo, agem pela ação direta para a constituição de "comunidades por vir" (política prefigurativa), estabelecendo uma negação da hegemonia, ou mesmo uma contra-hegemonia, constituindo um dual-power. Ou seja, constroem comunidades autônomas e em resistência, que operam - internamente como entre as lutas amigas - por outras normas que são a da afinidade, para ensaiar e constituir experiências que passam por fora do poder constituído. Eles buscam menos a irradiação no sistema de Estados e corporaçóes e focam nas possibilidades oferecidas pelo deslocamento e substituição desse sistema (DAY, 2006, p. 719).

Há um nó antagônico que unem a multiplicidade dos coletivos sociais contra o neoliberalismo:

O que todos esses eventos têm em comum é sua oposiçáo à agenda do capital globalizante e à ideologia neoliberal associada a ele, que traz privatizaçôes, desregulamentação e desemprego ao Norte global, e programas de ajuste estrutural e maior empobrecimento ao Sul global. Essa oposiçáa veio de todas as classes, grupos de identidade e causas, de todas as partes do mundo, e revigorou tanto entre ativistas quanto acadêmicos que veem nela um retorno do espírito contracultural dos anos 1960 (DAY, 2006, p. 728).

Também há outro nó, contra a militarização e o controle:

É precisamente contra este sistema internacional de controle que lutamos, em nome de uma globalização genuína.

[...] Essas conexốes - e as ligaçốes mais amplas entre as políticas neoliberais e os mecanismos de coerção do Estado (polícia, prisôes, militarismo) - desempenharam um papel cada vez mais saliente em nossas análises, à medida que enfrentamos níveis crescentes de repressão do Estado (GRAEBER, 2002, online).

Paolo Gerbaudo (2017) ainda diferencia o movimento anti-globalização dos movimentos que surgiram entre 2011-2016, como uma possível quarta geração. São semelhantes em essência (ação direta, formas de organização, uso da internet, política prefigurativa), com a exceção que agora são territorializados. É uma resposta ao advento do neoliberalismo e ao desmonte do Estado de BemEstar, quando os bens públicos terceirizados passam a ser gerenciado diretamente pelos interesses econômicos via terceirização. O chamado "populismo assembleário" ou "comuneiro" surge em resposta a esse processo, como um poder constituinte organizado para trazer novamente as questóes de interesse público para a sociedade civil de forma territorializada, agora dentro da estrutura social difusa em voga. 
No positivo, "a máscara" expressa fé no poder democrático de indivíduos "autônomos" e coletivos auto-organizados, como visto em uma série de práticas de movimento, desde o ethos de autogestão dos ocupantes de 68 até o governo autônomo dos zapatistas no México; o uso de tomadas de decisão baseadas em consenso por ativistas antiglobalização em seus movimentos de ação direta; e as novas práticas de colaboração online no movimento do software livre e em coletivos de hackers [...] A bandeira evoca algo totalmente diferente; estritamente falando, as bandeiras denotam controle sobre uma comunidade política, pelo menos parcialmente definida territorialmente (GERBAUDO, 2017, p. 4).

Os novíssimos movimentos sociais clamam por uma democracia que seja de baixo para cima, ocupando praças e transformando-as em ágoras, espaços onde a participaçáo progressivamente constituem um poder dos de baixo (GERBAUDO, 2017): “[...] Acampamentos de anarquistas protestando eram vistos como comunas autogeridas, prefigurando um mundo sem estado e governo" (GERBAUDO, 2017, p. 18).

Isso é o que chamam de prefigurative politics, ou seja, espaços políticos e decisórios autônomos que ensaiam tipos de participação direta e que crescem na medida que o sistema representativo entra em crise. Em seu léxico estão a decisão por consenso, horizontalidade, anti-autoridade (autonomia) e espaços não-hierárquicos (não-representação). Estes espaços são caracterizados por uma multiplicidade de "visóes de mundo", identidades e opiniôes: uma "multidão" polissêmica que faz política e difere ou mesmo se opóe à univocidade da lei e da soberania. Os movimentos sociais contemporâneos não reproduzem as organizaçôes tradicionais e, acima de tudo, não são sectários. Seguem outra lógica de organização, decisão e ética, prefigurando a sociedade futura:

[...] este é um movimento sobre reinventar a democracia. Não se opóe à organização. Trata-se de criar novas formas de organização. Não falta ideologia. Essas novas formas de organização são sua ideologia. Trata-se de criar e implementar redes horizontais em vez de estruturas de cima para baixo como estados, partidos ou corporaçóes; redes baseadas em princípios de democracia de consenso descentralizada e não hierárquica. Em última análise, aspira a ser muito mais do que isso, porque, em última análise, aspira a reinventar a vida quotidiana como um todo. Mas, ao contrário de muitas outras formas de radicalismo, ele primeiro se organizou na esfera política - principalmente porque este era um território que as potências constituídas (que mudaram toda a sua artilharia pesada para a econômica) abandonaram em grande parte (GRAEBER, 2002, online).

Não existe um consenso sobre a divisão de momentos e vertentes dos movimentos sociais. Mas entre todas as concepçôes diz-se sobre movimentos sociais contemporâneos que optam pela ação direta e por uma política prefigurativa, por vezes um dual power, ou seja, organização e resistência de comunidades autônomas em suas próprias regras vivíveis que são alternativas às políticas institucionais vigentes - ou por vezes intercalada com elas.

\section{PARTICIPAÇÃO POPULAR EM SÃO PAULO (2014)}

São Paulo é um município com grande crescimento na virada do século XIX para o Século XX:

Em 1874, a cidade de São Paulo tinha uma populaçáo de apenas 25.253 habitantes; em 1886, esse número ascendia a 44033 . O Censo de 1900 acusou uma população cinco vezes superior, de 239820 habitantes, número que dobraria vinte anos depois para 579 033 (SEGAWA, 2004, p. 15). 
Até então, somente o pequeno triângulo central era ocupado. O café, a ferrovia São Paulo Railway e a chegada de imigrantes são considerados os grandes responsáveis por esse crescimento acelerado da cidade (SEGAWA, 2004) que tem continuidade nas primeiras décadas. Em 1927, a Light já possuía um plano de construção, plano esse rejeitado pelo município (LAGONEGRO, 2004). Posteriormente, surge o plano de avenidas de Prestes Maia que acaba ocupando o leito dos rios com avenidas. $\mathrm{O}$ rápido crescimento era acompanhado de projetos urbanos modernistas e rodoviaristas. Nos anos de 1940, inicia-se um projeto de expansão urbana, processo facilitado com a troca da matriz ferroviária pela opção rodoviária (LAGONEGRO, 2004). O processo de constante projetos e obras rodoviárias contínua ao longo da ditadura militar, sendo o elevado Costa e Silva (atual João Goulart) símbolo máximo deste processo. No final dos anos 1970, São Paulo constrói sua primeira linha de metrô. Todos os processos até agora citados não contam com participação popular. Com o fim da ditadura militar, começa uma crescente ascensão dos movimentos populares e ascende a participação popular nas questôes urbanas, algo que ganha muita força a partir da eleição de Luiza Erundina para a prefeitura municipal (SILVA, 2017). A gestão contou com inúmeros debates contando com movimentos sociais, principalmente nas pastas de habitação e transporte, obteve como destaque para os mutiróes habitacionais. Também existiram importantes debates na questão do transporte coletivo gratuito e a criação de um plano diretor com extensa participação, plano esse que devido a conflitos de interesse nunca foi votado pela câmara dos vereadores (SILVA, 2017).

Com a criação do estatuto da cidade normatizam a necessidade de participação popular para as questôes urbanas e a gestão de Marta Suplicy cria as subprefeituras, que serviriam para descentralizar a administração pública e facilitar o acesso da população as decisóes que envolviam os seus respectivos território. Porém,

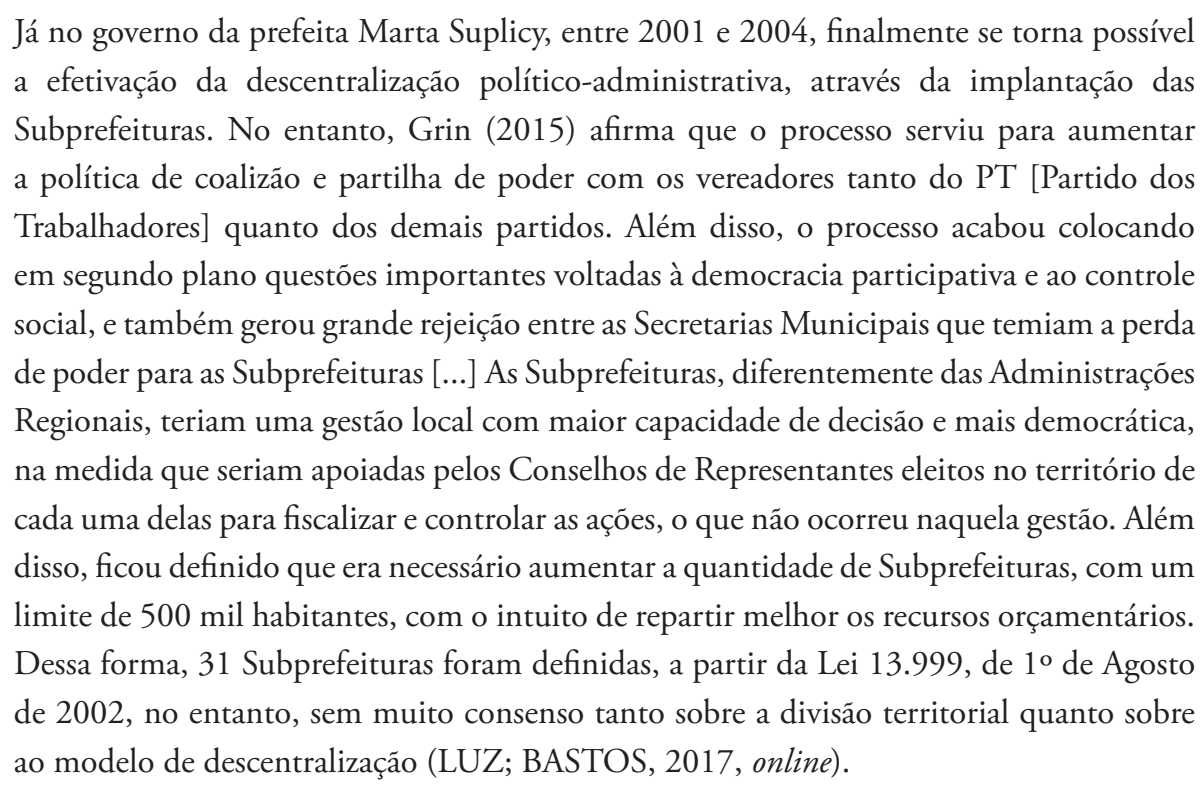

Do ponto de vista do planejamento urbano, a gestão de Marta Suplicy foi importante para a criação e aprovação de um novo plano diretor e uma nova lei de zoneamento, com debates divididos por subprefeituras, cada uma com o seu respectivo plano. Porém, Jorge Wilheim, responsável técnico pelo marco legal da gestáo, defende, posteriormente, em entrevista: 
Jorge Wilheim lamenta, porém, que a estrutura jurídica brasileira seja perniciosa ao permitir que uma lei discutida e aprovada pelas câmaras legislativas tenham de ser posteriormente regulamentadas pelo Executivo, por meio de decreto. "Se algum prefeito não quer fazer com que uma lei vingue, ele simplesmente deixa de regulamentá-la e a lei vira letra morta", critica. "Houve mais ou menos 30 artigos do PDE que até hoje não saíram do papel por simples falta de regulamentação da prefeitura (BREDA, 2012, online).

Posteriormente, a gestão de Gilberto Kassab apresentou uma proposta de projeto urbano para a região do bairro da Luz - projeto Nova Luz -, que não contou com participação da população, ainda que tal envolvimento seja obrigatório por lei. A repercussáo dada à repressão policial na região para colocar o plano a força chamou atenção para a questão junto a inúmeros protestos contestando a falta da participação popular na elaboraçáo do projeto, o que acabou adiando o começo das obras. $\mathrm{Na}$ gestáo Gilberto Kassab, uma nova proposta de plano diretor foi apresentada, porém o projeto também foi arquivado a partir de decisão do judiciário:

[...] liminar, concedida em 22 de maio pelo juiz Valentino de Andrade, suspendeu as audiências públicas agendadas em cima da hora pela prefeitura para garantir a aprovação do Plano Diretor. Segundo o promotor de Justiça Marcelo Ferreira de Souza Netto, tais audiências foram marcadas em prazos curtos demais "para a comunidade obter, conhecer, estudar, analisar e refletir as propostas de revisão (CARTA MAIOR, 2007, online).

Somente na gestáo de Fernando Haddad o marco legal urbanístico da cidade teve uma revisão. Partindo do princípio que a legislação então vigente (um plano para cada bairro) criava desconexôes no tecido urbano: efeito chamado de "colcha de retalhos", a iniciativa dividiu a área da cidade em diferentes zonas de acordo com a ocupação e infraestrutura de cada área. Ao mesmo tempo, criou eixos com base no transporte coletivo.

Audiências públicas foram realizadas em todas as subprefeituras, mas ao contrário do processo anterior onde o projeto era claramente voltado para as subprefeituras, criando debates sobre questôes pontuais de cada subprefeitura, desta vez isso não foi possível: não foram criados planos para cada subprefeitura em que a população podia atuar sugerindo criação de intervençóes na escala do bairro, tal como parques, obras viárias pontuais, entre outros casos.

Embora tenha gerado um grande impacto de mídia e presença em audiências, não existiu um processo que de fato encaminhou uma construção em conjunto para o planejamento. Cada subprefeitura recebeu duas audiências: uma primeira, de apresentação, e algumas semanas depois, após a população poder encaminhar propostas via internet (entre outros meios) existiu uma audiência de retorno em cada subprefeitura.

\section{EXISTE DESCENTRALIZAÇÃO DE GESTÃO PARA UM GOVERNO POPULAR EM SÃO PAULO?}

As duas últimas décadas contaram com reformulaçôes do marco legal urbanístico do Município de São Paulo que prevê participação popular. Foram criados um novo Plano Diretor Estratégico, uma nova Lei de Uso e Ocupação de Solo, um novo Código de Obras e Edificação. O Plano Diretor afirma a necessidade legal de discussão nos fóruns públicos (audiências públicas, conselhos participativos distribuídos nas subprefeituras) para legitimar as reformas, ou seja, uma reforma 
pode ser embargada se não passou pelos fóruns previstos em lei. As eleiçóes municipais de 2020 já demonstraram a preocupação em revisar novamente o marco legal. Enquanto o Partido dos Trabalhadores (PT) defende que deve-se ancorar em intensa participação popular para transformar a cidade de São Paulo em um "espaço mais humano", a coalizão Partido da Social Democracia Brasileira e Democratas (PSDB/DEM) argumenta que ela dificulta a atuação do mercado e construção imobiliária. Se para os últimos poderíamos alegar espanto que o debate não se pauta na qualidade da produção do espaço e sim na produção imobiliária, ou seja, o território olhado sob a perspectiva de mercadoria e não na qualidade do território para os cidadãos, para os primeiros, o marco legal representa uma grande ferramenta de expressão da vontade popular em busca da melhor qualidade territorial.

A questão a ser respondida é quem de fato produz a elaboração do marco urbanístico municipal. Trata-se de uma legislação, como todas, com cunho político muito maior do que o cunho técnico. Vale a pergunta: é nas audiências que os portadores de grande capital financeiro e imobiliário expressam suas vontades para os representantes da municipalidade?

Flávio Villaça, professor aposentado da Faculdade de Arquitetura e Urbanismo da Universidade de São Paulo (USP), escreveu um conhecido trabalho chamado As Ilusóes do Plano Diretor (2005). Villaça acompanhou as audiências públicas para o plano diretor que eram necessárias para a aprovação da lei. Chegou a algumas conclusôes. A abissal desigualdade social regional no Brasil leva a uma desigualdade de participação. Os bairros de maior renda contaram com maior participação, enquanto os de menor renda contaram com pouca participação. De qualquer forma, os empresarias dos negócios locais pouco compareceram e houve total ausência dos empregados do bairro (VILLAÇA, 2005, p. 65). Apesar do quórum ter sido sempre muito reduzido, as organizaçóes populares que compareceram eram nos bairros já mais estruturados e essas organizaçóes eram compostas principalmente pela classe média e média-alta, mais politizadas, que tiveram conhecimento prévio das audiências e que eram capazes de participar (VILLAÇA, 2005, p. 64). De qualquer forma, a participação popular foi dificultada mesmo para a pequena burguesia e classe média, sendo que as principais propostas de modificação do zoneamento "diziam respeito aos territórios e interesses das elites paulistanas" (VILLAÇA, 2005, p. 48). Essas elites não participam dos fóruns e fazem sua política muitas vezes por outros canais que possuem acesso, às vezes diretamente com o poder político que tem acesso, através do lobby, ou mesmo pelos canais de comunicação:

\footnotetext{
É essa ilusão que a recente ênfase em Plano Diretor Participativo - querendo ou não procura inculcar na opiniáo pública. O que raramente aparece é que os grupos e classes sociais têm não só poderes político e econômico muito diferentes, mas também diferentes métodos de atuação, diferentes canais de acesso ao poder e, principalmente - algo que se procura sempre esconder - diferentes interesses. [...] Assim, os debates públicos seriam apenas a ponta de um iceberg, ou seja, aquilo que não aparece é muito maior do que a parte que aparece. [...] $\mathrm{Na}$ verdade uma substancial parcela dessa atuação se manifestou (como acontece com quase toda lei) através de pressóes, principalmente as exercidas sobre os vereadores, e não em debates públicos (VILLAÇA, 2005, p. 50-51, online).
}

Não encontraremos então os principais agentes do processo nos conselhos participativos ou nas audiências. Não encontraremos nos conselhos de segurança ou nos conselhos participativos das subprefeituras, mas os seus interesses estão lá atuando, já que a definição desses espaços - começando pela indicação dos subprefeitos - passam por uma rede de poder que essas elites se fazem 
presentes. Existe uma zona cinzenta entre as principais famílias da elite paulistana, os clubes da cidade, as instituiçôes religiosas e os partidos políticos.

Em outra pesquisa de campo analisamos a região Brás-Mooca-Belém ${ }^{6}$ Se tomamos essa região como exemplo veremos a influência de famílias como a Comolatti com diversos empreendimentos na região, ou a atuação de subprefeitos oriundos de famílias das elites locais ou que são também quadros importantes de partidos políticos - ali, no caso, as ligações são com o PSDB. Todos esses atores se encontram em espaços sociais próprios, como o Circolo Italiano, Clube Paulistano, Rotary Club, Clube Parque da Mooca e, principalmente, Clube Atlético Juventus. Ou nos seus templos, sendo ali na Mooca a maioria católica. Ou às vezes os subprefeitos já passaram por empresas de economia mista ou cargos de confiança, como a Companhia de Saneamento Básico do Estado de São Paulo (SABESP) ${ }^{7}$, ou possuem relaçóes com OSs que prestam serviços de zeladoria urbana para a prefeitura. A atuação destes atores geralmente não se dá dentro dos conselhos participativos da cidade, mas como ficou evidente, os seus interesses estão sendo pautados em alguns conselhos, como por exemplo os Conselhos de Segurança (CONSEGs), uma das principais demandas do bairro.

A participação popular nas audiências públicas ou nos conselhos participativos não são intensivas na Cidade de São Paulo como é na cidade de Buenos Aires e na sociedade argentina, muito mais orgânica. A participação popular em São Paulo é um processo recente e que avançou principalmente com as poucas gestóes do Partido dos Trabalhadores. De qualquer forma, sofre com todas as advertências que o Prof. Villaça sugere. Vale lembrar que mesmo os Conselhos Participativos das Subprefeituras é algo bastante recente e que não consegue manter atividade regular com as trocas de gestôes. Diferente da Argentina, onde a administração das Comunas da Cidade é direta através de um Conselho eleito com diversas competências executivas e orçamentárias, em São Paulo o subprefeito é indicação do Prefeito da cidade, dificultando a continuidade dos trabalhos. Tivemos mesmo dificuldade em conseguir atas de reuniôes das subprefeituras, já que a Subprefeitura passa essa responsabilidade aos Conselhos Participativos que ainda náo estão suficientemente organizados, ao mesmo tempo que quando muda de gestão se torna mais difícil ter acesso aos documentos da gestão anterior.

Observaremos a seguir o caso argentino.

\section{PARTICIPAÇÃO POPULAR EM BUENOS AIRES (2018)}

Entendemos que, após a democratização, a cidade de Buenos Aires (igualmente como em outros espaços da América do Sul) passou por um rearranjo tardio do segundo ciclo de participação (ex: audiências públicas), mas rapidamente avança para o terceiro (gestão compartilhada). É apenas em 1996 que Buenos Aires consolida sua autonomia administrativa, quando determina os mecanismos de participación ciudadana.

\section{ALGUNS ANTECEDENTES HISTÓRICOS}

A política argentina como foi definida no século XX - nos governos de Yrigoyen e Perón - é um caso sui generis, mesmo entre seus irmãos e vizinhos. É possível que tenha contribuído para isso

\footnotetext{
$6 \quad$ Pesquisa de doutorado de Guilherme Giuliano Nicolau, ainda a ser publicada.

$7 \quad$ Dos atores que comentamos aqui, Fábio Lepique e Criscuolo foram da Companhia Paulista de Obras e Serviços (CPOS). O atual subprefeito da Mooca, Guilherme Britto, também foi diretor da CPOS.
} 
a sua histórica específica de acumulação primitiva, ou seja, como foi conquistada a propriedade privada junto a sua questão de terras (diferente entre a colonização portuguesa e a espanhola), o elevado desenvolvimento econômico e industrial do período comparado a seus vizinhos mais próximos como o Brasil, a concentração populacional reduzida à província de Buenos Aires (mais especificamente a cidade de Buenos Aires), e por fim, uma população consideravelmente menor que de países vizinhos como o Brasil.

\section{UMA EXPERIÊNCIA ASSEMBLEARIA, UM RESULTADO COMUNERO}

A Constituição de Buenos Aires surge em 1996. Definiu-se a autonomia da Cidade e o cargo de prefeito eleito, bem como constituiu os seus mecanismos de participação popular, definiu audiências públicas e iniciativas populares como mecanismos de participação popular.

A política argentina já funcionava de maneira distinta e territorial, através das Unidades Básicas do Partido Justicialista (peronistas) e seus punterosmas de cima para baixo (como o é a política de seu tempo $)^{8}$. Com a crise social e econômica de 2001, gerou-se um e o vazio político em termos de representação, preenchido e disputado nas ruas pela população que começou a compor os novos movimentos sociais do século XXI. Uma "zona cinzenta" opera dentro do espaço social em que diferentes forças e maneiras de se fazer política coexistem e disputam entre si, sejam as mais tradicionais ou as mais inovadoras.

Alguns movimentos e organizaçôes que podemos destacar foram a dos piqueteros (o Movimiento de los Desocupados sendo o mais atuante no período), as fábricas recuperadas, as Asambleas de Barrio, também as manifestaçóes conhecidas como cacerolazos. Nessa disputa política das pulsóes das massas em um período de tensão social, esses espaços foram se adequando conforme a normalidade e um novo pacto social se estabeleciam com a capacidade de mobilização do kirchnerismo? .

Os cacerolazos (bater panela), ativos entre a classe média urbana para demonstrar insatisfação com a classe política durante o ano de 2001 porque haviam confiscado suas poupanças em dólares, foi mitigado conforme sua vida cotidiana e suas necessidades foram normalizadas e começaram a dar resposta às suas reivindicaçóes. Os piqueteros, pertencentes aos setores populares, ficaram conhecidos por fechar vias e usarem táticas de confronto com as forças policiais, sendo duramente reprimidos; algumas dessas organizaçóes fizeram parte de programas de Cooperativas de Vivienda (autogestão e autoconstrução de habitat, semelhante ao que conhecemos como mutiróes de habitação no Brasil), houveram cisóes entre outros que optaram por seguir pela via parlamentar e os que permaneceram nas ruas, e entre a radicalização nas províncias (periferia) e assentamento da cidade. As fábricas recuperadas, que estabeleceram estratégias de autogestão entre trabalhadores que tomaram controle de fábricas que foram à falência e abandonada por seus proprietários, foi incorporada a programas de economia solidária e organizadas em federaçóes, participando de programas internacionais, mas também muitas chegaram à exaustão.

As Asambleas de Barrio foram uma experiência única na história argentina, com diversas novidades de mobilização típicas de nossos tempos e que abrangeu diferentes classes sociais. Diz-se, por exemplo, que mesmo entre a classe média de Palermo não havia capacidade de adquirir bens para alimentar suas famílias quando passaram a trocar bens e alimentos e praticar a solidariedade

8 Também havia organizaçóes territoriais de outros partidos políticos, como a Unión Cívica Radical.

9 Muitos tornaram-se, também, dependentes do novo ciclo político. Uma vez que Macri foi eleito, suas atividades foram reprimidas e cortaram recursos. A Organización Barrial Tupac Amaro, por exemplo, que possuía fábricas têxteis e construiu bairros populares junto a cooperativas de habitaçáo, teve seus programas interrompidos e uma de suas lideranças, Milagro Sala da Província de Jujuy, foi perseguida politicamente e encarcerada, assim como outros líderes dessa organizaçáo. 
ou, em muitos casos, tinham que ir a comedores populares dos quais também estavam ativos nas assembleias. A generalização da crise econômica junto com o vazio político estabelecido pela crise de representação (que se vayan todos) exigiu inovação política das bases sociais que estabeleceu o cotidiano nesse período em uma sociedade que já estava habituada às políticas barriais - antes centralista no organicismo peronista - que fez um exercício de inverter a ordem e trazer as decisóes para baixo; sem dúvida, também favoreceu a subjetividade urbanística do planalto bonaerense que possui bairros bem definidos, com vida e identidade própria.

As Assembleias lograram algum tipo de autonomia territorial de baixo para cima, mas perderam sua força com o tempo; no entanto, esse acúmulo contribuiu para, em 2005, serem aprovadas duas leis incorporadas à Constituição de Buenos Aires: de Mandato Revogável(20\% do eleitorado para revogar um mandato); Lei de Comunas ${ }^{10}$. Atentaremo-nos no próximo ponto, como constituiu-se a Lei de Comunas (durante o mandato de Ibarra) e como foi sua participação posterior no processo de aprovação do novo código urbanístico sob a gestão Macri/Larreta.

É necessário observar antes que, como típico da organicidade da política argentina, essas são zonas bastante cinzentas disputadas por diversas posiçóes políticas e estratos sociais ou mesmo ofícios, verticais ou horizontais, à esquerda ou à direita, centrais ou periféricas, radicais ou moderadas. Não, é claro, sem contradiçóes a confrontarem-se. Frequentemente encontrar-se-ão os mesmos coletivos e indivíduos circulando entre os mesmos espaços ${ }^{11}$.

\section{O MOVIMENTO COMUNERO}

Uma vez aprovada a Lei de Comunas, em 2005 (Ley 1777), a partir de manifestação espontânea dos bairros e com participação ativa dos vizinhos no processo, o novo governo da cidade comandado por Macri, em 2008, não reconhecia as autoridades comunais. Entendem como seu objetivo:

A integração da Cidade de Buenos Aires em Comunas participativas - nosso principal e único objetivo - tem o duplo propósito de criar governos de bairro e promover a tomada de decisóes e o controle cidadão das açóes governamentais em um espaço local visível, palpável e controlável no qual habitamos (MOVIMIENTO COMUNERO, 2019, online).

O novo governo da cidade, além de dificultar a realização das comunas (as primeiras eleições só foram ordenadas em 2008 e realizadas em 2011), tentou por impor outra administração ligada ao seu gabinete, o que levou os vizinhos dos diferentes bairros a criarem o Espacio Intercomunal e criar os Consejos Comunales de forma autoconvocada ${ }^{12}$ (como previsto em lei). Pressionando o Legislativo para realizar as eleiçóes desde as bases políticas do Movimento Comunero, foi a primeira grande derrota legislativa de Macri na capital.

10 É interessante notar que, tanto o mandato revogável e a divisão de comunas em uma cidade, foram ensaiadas na Comuna de Paris em 1871 - obviamente náo queremos dizer tratar-se da mesma coisa, o que seria um anacronismo, mas apontamos para ordens que estão no imaginário político e popular já há algum tempo.

11 Ou frequentemente encontraremos cruzamento entre as práticas: na Asamblea Tupac Amaru, em Congreso, constituem um espaço de encontro e reunião para questôes externas e do bairro, são liderados pelo ativismo de Milagro Sala De Jujuy, um nó que esteve por muito tempo ligado tanto aos piqueteros como a sindicatos como a CTA, e obtiveram bastante recursos durante os mandatos dos Kirchners.

12 Assim é comum fazer-se chamados em torno das Asambleas e Comunas, diz-se normalmente "vecinxs-autoconvocadxs". 
Segundo a Ley 1777/05, o governo das comunas é constituído por um órgão colegiado de 7 membros, chamado Junta Comunal, eleito pelos cidadãos residentes da Comuna. Para ser candidato é necessário ser argentino ou naturalizado, no caso do último, ter exercido cidadania nos últimos dois anos. Os mandatos têm duração de 4 anos, podendo o candidato ser reeleito uma vez. Sua remuneração é correspondente a $60 \%$ dos deputados da cidade. A Junta Comunal pode convocar Audiências Públicas e Consulta Popular. Cada Junta Comunal possui um Consejo Consultivo Comunal, com participaçáo de diversos setores da sociedade civil dentro do bairro, incluso os próprios residentes enquanto indivíduos, que autoconvocam reunióes regulares para deliberar em apoio à Junta Comunalas açôes de seu mandato. Existe ainda o Consejo de Coordinación Intercomunal, onde as Juntas se encontram para discutir a cidade de maneira total.

Há, porém, uma forte pressão nas juntas comunais pela inserção macrista que busca ou a centralização ou o congelamento dessa estrutura de participação ${ }^{13}$, que é por outro lado garantida pelo MovimientoComunero.

\section{O NOVO CÓDIGO URBANISTIICO E A PARTICIPAÇÃO DAS COMUNAS}

O ano de 2018, em que fizemos campo, foi um momento de uma agressiva investida do governo Macri/Larreta na Cidade de Buenos Aires, enquanto aprovavam um novo código urbanístico e de edificação. Junto com a chamada para grandes eventos como o G20 e os Jogos Olímpicos da Juventude, vendia-se Buenos Aires como uma Cidade Global. Houve fortalecimento da segurança pública (com Patrícia Bullrich no Ministério de Segurança) e uma investida contra a "marginalidade", criminalizando a população mais jovem e pobre (caso Chocobar), os artistas de rua e a população em situação de rua. Mudanças cosméticas foram estabelecidas na cidade, diversas ordens de reintegração foram cumpridas, inúmeros espaços públicos (como o Centro Nacional de Alto RendimientoDeportivoem Nuñez) foram transferidos sem consulta à populaçáo (obrigatório por lei) e a cidade foi redesenhada em diferentes polos desconsiderando as populaçóes vulneráveis nos bairros (ex: Casa Santa Cruz em Parque Patricios, o novo polo tecnológico).

Houve, também, grande mobilização popular com conquistas legislativas. Em Outubro aprovou-se a Ley 27.453 (Ley de los Barrios Populares) em que se reconheceu o direito a terra de 930.000 famílias em nível nacional, garantiu o direito a expropriação de terrenos onde estão registrados esses bairros, e suspendeu os desalojos por 4 anos. Avançou-se a construção de moradia popular para a população vulnerável em Playon de Chacarita e em Retiro para a Villa 31. As Comunas e Assembleias se organizaram de forma ativa nas questóes urbanas e transformaçóes da cidade.

Durante a votação do Novo Código Urbanístico, assistido por mecanismos digitais com participação de pesquisadores da Universidade de Buenos Aires e organizações da sociedade civil (Observatório del Derecho a La Ciudad), sindicatos e movimentos autônomos, os bairros conseguiram se organizar para apresentar cada problema local detalhado e as consequências do código. Fizeram-se frequentes e organizados, com cartazes e protestos durante as audiências, aparecendo a cada audiência referida os moradores do bairro que apresentavam em detalhes os problemas que colocavam o novo código em sua regiáo. Enquanto, por exemplo, em uma audiência sobre o bairro

13 Um exemplo que observamos em campo: a Ley 3343 para urbanização da Villa 31 náo foi feita de forma transparente, adquirindo um caráter de resistência popular da comunidade, que pressionou maior clareza nas audiências públicas que acompanhamos. O Macrismotambém inseriu-se na Villa 31, tornando-se um espaço de disputa. Há um intuito claro. Dentro da lei, há a previsão de participação popular e decisão a partir da comunidade, mas também prevê que, caso não obtenham consenso, é o governo da cidade que decide: uma vez estabelecido o antagonismo nesse espaço social, náo é possível o consenso. 
de Agronomía, os vizinhos - a maioria - alertavam para como os "espigóes" iriam descaracterizar o bairro ("nos arredores da faculdade, encontram-se ainda cavalos e espaços verdes"), representantes macristas ligados ao Instituto di Tella (organismo universitário privado) apresentavam relatórios tratando de demonstrar com fundamentação técnico-científica a viabilidade de substituir os espaços verdes públicos por tetos verdes no topo dos edifícios privados, com a justificativa que poderiam amenizar os alagamentos.

O ativismo para conter o Novo Código Urbanístico logrou grandes reuniōes entre diferentes Comunas e vecinos, utilizando-se massivamente das redes sociais para colocar-se em ação e fazer-se conhecer o que implicava as transformaçôes que o código impunha para a cidade e para cada bairro. Isso veio a constituir-se como uma grande assembleia virtual (com encontros físicos regulares) denominada Asamblea Ciudadana. Um consenso estabelecido nessas assembleias seria que, pela lei de comunas, qualquer transformação em um bairro teria que passar por consulta às comunas, algo que não estaria acontecendo, sendo assim os comuneros alegavam ser uma manobra ilegal da gestão executiva da cidade.

E quais foram os resultados materiais, além do acúmulo organizacional dos movimentos sociais?

O Novo Código Urbanístico e de Edificação foi aprovado atropelando a participação das Comunas, como as intervençôes e recomendações dos vizinhos nas audiências públicas. Nele definiu-se, por exemplo, que os apartamentos poderiam passar de um mínimo de 30 metros quadrados para 18 metros quadrados; sobe consideravelmente a altura permitida pelos edifícios (regularizando 'torres' que já haviam sido construídas em bairros como Villa Pueyrredon) e exige que sejam nivelados por cima (ou seja, todos os edifícios mais baixos devem se adequar aos mais altos); as exigências de materiais mudaram, e a espessura passou de $25 \mathrm{~cm}$ para $5 \mathrm{~cm}$, permitindo o uso de material não-durável como compensado; permite avançar a frente dos edifícios diminuindo o espaço de circulação; diminui os retiros, espaços verdes e parques.

\section{APROXIMAÇÕES, DISTANCIAMENTOS}

Apesar da Argentina ter completado o ciclo assembleario bastante antes da chegada de Macri, o processo atropelado - sendo um sintoma dos tempos atuais, autocrático aqui e no mundo. A América do Sul dos anos 1990 a hoje costuma estar na vanguarda popular em sua forma política, mas com condições materiais e econômicas adversas (desindustrialização, crise fiscal e neoliberalismo).

O populismo argentino foi mais orgânico que o caso brasileiro, integrando-se ao do sindicalismo bastante ativo no país, mesmo de forma territorial. Em um período em que a classe trabalhadora (tanto na Argentina, como no Brasil) organizava-se em espaços sociais nas suas comunidades e bairros, com centros culturais, ateneos, grêmios, o peronismo fez sua inserçáo nos bairros e quarteirôes através do que se denominou Unidades Básicas do Peronismo - que possibilitaram coletar as necessidades e demandas de cada região, dando resposta ao transferir recursos e bem-estar. Isso também serviu para garantir a sua base eleitoral entre o povo Começa a configurar-se aqui um personagem conhecido da política argentina que é o puntero $^{14}$ : um mediador, uma liderança local que, articulada com as classes políticas através das organizaçôes políticas orgânicas, faz a ponte entre

14 Segundo Auyero (2007, p.204) outra denominaçáo comum na mídia para os 'punteros' seria “dirigentes barriales peronistas". 
a necessidade eleitoral de seus políticos aliados e as necessidades de sobrevivência da comunidade que representa. As ditaduras da Argentina fizeram um grande esforço para aniquilar o peronismo e sua organicidade, mas ele manteve-se vivo na sociedade permanecendo vivo na sociedade argentina, voltando de forma oficial e evidente no período de redemocratização, tendo sua maior popularidade com a vertente de centro-esquerda em torno do kirchnerismo.

O histórico do planejamento urbano no Município de São Paulo, como vimos, tem problemas em continuidade. A falta de uma atividade contínua de participação acaba dificultando a criação do hábito de participar ativamente dos processos e audiências. A falta de diálogo estabelecida recorrentemente pelo Estado também cria uma descrença nos processos participativos. A participação acaba acontecendo apenas quando determinados grupos lutam por alguma pauta específica e, uma vez atingido o objetivo, deixam de participar da rotina dos projetos urbanos do município.

A Argentina, que também passou por uma ditadura com caráter de supressão de participação popular, possui um histórico de organização popular a partir do Peronismo, que é mais presente no cotidiano da população, mas que também são ignorados diante da conjuntura política atual.

Para ambos os casos, parece-nos que o governo utiliza a seu favor o resguardo de "participação popular" para legitimar determinadas açóes que vão de encontro ao seus interesses já que é obrigatório por lei, mas não levam em conta as audiências quando elas se mostram um grande impeditivo para a aprovaçáo de seus projetos.

\section{CONCLUSÕES}

Este trabalho buscou correlacionar os temas trabalho, movimentos sociais, planejamento urbanístico e municípios. Partimos do pressuposto que as teorias de movimentos sociais, principalmente pós-Maio de 68, enquadraram essa correlaçáo rebaixando trabalho enquanto categoria sociológica fundamental.

Com a finalidade de superar a falsa dicotomia trabalho $\mathrm{x}$ movimentos sociais nos projetos urbanísticos das cidades, propusemos realizar uma comparação entre duas cidades latino-americanas no que diz respeito ao acesso à cidade: São Paulo, para o ano de 2014, e Buenos Aires, para o ano de 2018. Nossa metodologia se focou na participação em audiências públicas de ambos municípios e levantamento histórico urbanístico das cidades.

Primeiramente, abordamos teorias de movimentos sociais que demonstram o apagamento da centralidade do Estado e do trabalho como forma de dissolução das desigualdades sociais até a "terceirização" de diminuição (não mais dissolução) dessas desigualdades para os municípios, com a finalidade de entender melhor nosso objeto. Em seguida, apresentamos a participação popular nas duas cidades em questão, pela linha do tempo dos planejamentos urbanísticos para então apresentar a participação em audiências públicas dessas cidades. Por fim, apresentamos aproximaçóes e distanciamentos (a comparação) entre ambas experiências.

Nossos resultados demonstram que, a despeito de mudanças (ou "avanços") normativos institucionais relevantes no que diz respeito à entáo chamada cidadania (termo comum dentre os novíssimos movimentos sociais), o entrave a tal participação plena são justamente os problemas apresentados pelos "velhos" movimentos sociais, ou seja, a inserção da América Latina em problemas mais estruturais que dizem respeito às condiçóes materiais de exercício pleno da chamada cidadania. Desta forma, entendemos que com o período de redemocratizaçáo nos países do Cone Sul, superou-se alguns atrasos normativos referentes à cidadania, mas em condiçóes históricas bastante 
desfavoráveis como o neoliberalismo (terceirização da gestão pública para empresas e igrejas) e a ascensão progressiva do autoritarismo (que deram mais proeminência aos Conselhos de Segurança do que os Conselhos Cidadãos).

\section{REFERÊNCIAS BIBLIOGRÁFICAS}

ARCHDAILY BRASIL. Flávio Villaça morre aos 91 anos em Sáo Paulo. Disponível em: https://www. archdaily.com.br/br/959353/flavio-villaca-morre-aos-91-anos-em-sao-paulo. Acesso em: 12 jun. 2021.

AUYERO, Javier. La zona gris: violenciacolectiva y política partidaria en la Argentina contemporánea. Buenos Aires: Siglo XXI editores, 2007.

BREDA, Tadeu. P: Plano Diretor teve participação social, mas esbarrou na falta de vontade política. Rede Brasil Atual, Cidades, 6 set. 2012. Disponível em: https:/www.redebrasilatual.com.br/cidades/2012/09/ plano-diretor-teve-participacao-social-mas-nao-foi-totalmente-implementado-por-falta-de-vontade-political. Acessoem: 1 jun. 2019.

DAY, Richard F. Day. From hegemony to affinity, Cultural Studies, [s.l.], vol. 18, n. 5, p. 716-748, 2004.

GERBAUDO, Paolo. The Mask and the Flag. Oxford: Oxford University Press, 2017.

GORZ, André. Adeus ao proletariado. Rio de Janeiro, Forense Universitária, 1982.

GRAEBER, David. The new anarchists. New Left Review, [s.l.], vol. 13, p. 61-73, 2002.

Disponível em: https://newleftreview.org/issues/ii13/articles/david-graeber-the-new-anarchists. Acesso em: 1 jun. 2020.

LAGONEGRO, Marco Aurélio. 2004. Metrópole sem metrô: transporte público, rodoviarismo e populismo em São Paulo (1955-1965). Tese de Doutorado - Universidade de São Paulo, São Paulo, 2004.

LUZ, Ana Paula Ferreira; BASTOS, Valéria Pereira. A gestão participativa na cidade de São Paulo: formulação da política urbana local. Anais do XVII Enanpur, São Paulo, 2017. Disponível em: http://anpur.org. br/xviienanpur/principal/publicacoes/XVII.ENANPUR_Anais/ST_Sessoes_Tematicas/ST\%2010/ST\%20 10.3/ST\%2010.3-01.pdf. Acesso em: 1 jun. 2019.

MOVIMIENTO COMUNERO. Quien Somos. Disponível em: http://www.movimientocomunero.com. ar/quienes2.htm. Acesso em: 1 jun. 2019.

QUIROGA, Nicolás. Las Unidades Básicas Durante el Primer Peronismo. Cuatro Notas Sobre el Partido Peronista a Nivel Local. Buenos Aires: Mundo Nuevo, 2008.

SEGAWA, Hugo. Prelúdio da Metrópole. 2a ed. São Paulo: Ateliê Editora, 2004.

SILVA, Milena. A Gestáo de Luiza Erundina (1989-1992): Participação Popular na Política de Transporte. 2017. 208p. Dissertaçáo (Mestrado) - Universidade de Sáo Paulo, Instituto de Arquitetura e Urbanismo, São Carlos, 2017. 
VILLAÇA, Flávio. As Ilusôes do Plano Diretor. Disponível em: http://www.planosdiretores.com.br/downloads/ilusaopd.pdf. Acesso em: 1 jun. 2019.

WILliamSON, Abigail; FUNG, Archon. Mapping Public Deliberation. Disponível em: https://hewlett. org/wp-content/uploads/2016/08/MappingPublicDeliberation.pdf. Acesso em: 5 ago. 2018.

Public Deliberation: Where We Are and Where We Can Go? Disponível em: http://www.fisherwilliamson.com/downloads/FungWilliamsonNCR04.pdf. Acesso em: 4 ago. 2018.

Essa pesquisa foi financiada com recursos do Conselho Nacional de Desenvolvimento Científico e Tecnológico (CNPq) (processo $\mathrm{n}^{\circ}$ 141792/2016-7), Brasil, e do Consejo Nacional de Investigaciones Científicas y Técnicas (CONICET), Argentina. 